\title{
Inflammatory Myofibroblastic Tumor in a Known Case of Squamous Cell Carcinoma of Same Site - A Rare Case Report with Review of Literature
}

\section{Srinitya Mulukutla ${ }^{1 *}$, Shubhra Sharma ${ }^{1}$, Sachin Wani ${ }^{2}$, Hiral Shah ${ }^{3}$ and Ankit Shah ${ }^{2}$}

${ }^{1}$ Fellow, Department of Head and Neck Surgical Oncology, HCG Cancer Centre, India ${ }^{2}$ Consultant, Department of Head and Neck Surgical Oncology, HCG Cancer Centre, India

${ }^{3}$ Consultant, Department of Histo-Pathology, HCG Cancer Centre, India

*Corresponding Author: Srinitya Mulukutla, Fellow, Department of Head and Neck Surgical Oncology, HCG Cancer Centre, Vadodara, Gujarat, India.
Received: April 14, 2021

Published: May 05, 2021

(C) All rights are reserved by Srinitya

Mulukutla., et al.

\begin{abstract}
Background: Inflammatory myofibroblastic tumor is a rare and distinct disease entity comprising of myofibroblastic cells with inflammatory infiltrate. It was first described in the lungs in 1939 and since then few reports have been made of its occurrence in the oral cavity. As it clinically and radiologically mimics a malignant lesion, the correct diagnosis is imperative to avoid radical treatment.

Methods: We describe a case of 44 year male with a significant past history of squamous cell carcinoma of buccal mucosa, presenting with Inflammatory myofibroblastic tumor arising from same site. Patient presented with a solitary, well circumscribed lesion arising from buccal mucosa and gingival sulcus.

Results: Final histopathology was suggestive of inflammatory myofibroblastic tumor showing compact proliferation of spindle cells arranged in a storiform pattern, with predominantly lymphoplasmacytic cells infiltration.

Conclusion: Inflammatory myofibroblastic tumor can be accurately diagnosed with thorough understanding of histology and immune profiling which avoids unnecessary and extensive treatment protocols. No other case with a previous history of Squamous cell carcinoma of same site has been reported in literature.
\end{abstract}

Keywords: Buccal Mucosa; Inflammatory Myofibroblastic Tumor; Oral Squamous Cell Carcinoma

\section{Abbreviations}

IMT: Inflammatory Myofibroblastic Tumor; VD: Vimentin and Desmin; VAD: Vimentin, Actin, and Desmin; VA: Vimentin and Actin; ALK: Anaplastic Lymphoma Kinase

\section{Introduction}

Inflammatory myofibroblastic tumor (IMT) represents a wide spectrum of spindle cell proliferation ranging from reactive lesions to benign neoplasms and to more aggressive or even malignant lesions. It has been first reported in Lung by Brunn in 1939 with recent extra pulmonary IMT occurring in most organs and anatomic sites [1,2]. The incidence of IMT in head and neck region ranges from $14-18 \%$ [1]. Various pathogenic factors have been implicated in the pathogenesis of IMT, but its precise etiology remains unclear to this day. Here we report an unusual case of IMT of Buc- cal mucosa of a patient with a previous history of squamous cell carcinoma of same site.

\section{Case Report}

A 44 year male presented with a 4 months history of a well circumscribed, solitary, slow growing lesion in the left buccal mucosa and gingival sulcus (Figure 1 and 2). His medical history was unremarkable but had a significant surgical history of wide excision with segmental mandibulectomy, modified radical neck dissection type III with a pectoralis major myocutaneous flap reconstruction for Squamous cell carcinoma of left buccal mucosa in 2016. He received concurrent chemo radioatherapy as adjuvant treatment as per the merit of his histopathology report. Following this, patient was asymptomatic for 2 years. He presented in February 2019 with above complaints. A biopsy at that point revealed no evidence of 
dysplasia or malignancy. Patient was advised close observation and a repeat biopsy after 2 months was suggestive of rhinoscleroma. Patient was referred to an ENT specialist who advised a CT scan. The scan was unremarkable except for a plaque like thickening in Buccal mucosa. A review of the biopsy was consistent with rhinoscleroma. Patient was advised active surveillance at regular intervals. Two months later, patient presented with a repeat biopsy report suggestive of squamous cell carcinoma of same lesion certified by a senior pathologist. Clinical examination revealed, a mass measuring $4 \times 3 \mathrm{~cm}$ in the left upper buccal mucosa and gingival sulcus anteriorly. The growth was abutting the roots of left upper premolars. The sudden increase in size of lesion correlated with the biopsy report was perceived to be a recurrence. Hence a surgical resection and reconstruction with radial artery fore arm free flap was performed. The post-operative course was uneventful.

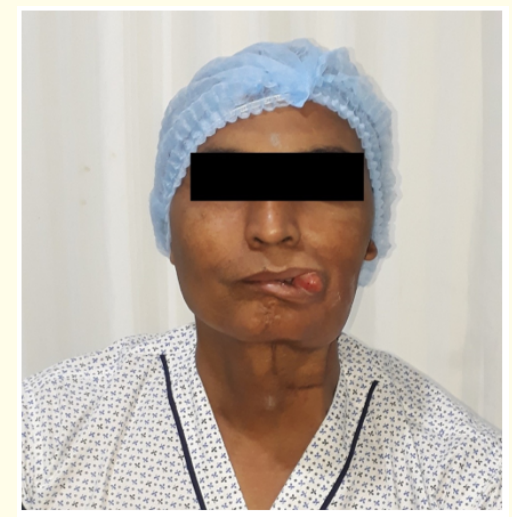

Figure 1: Clinical photograph of patient.

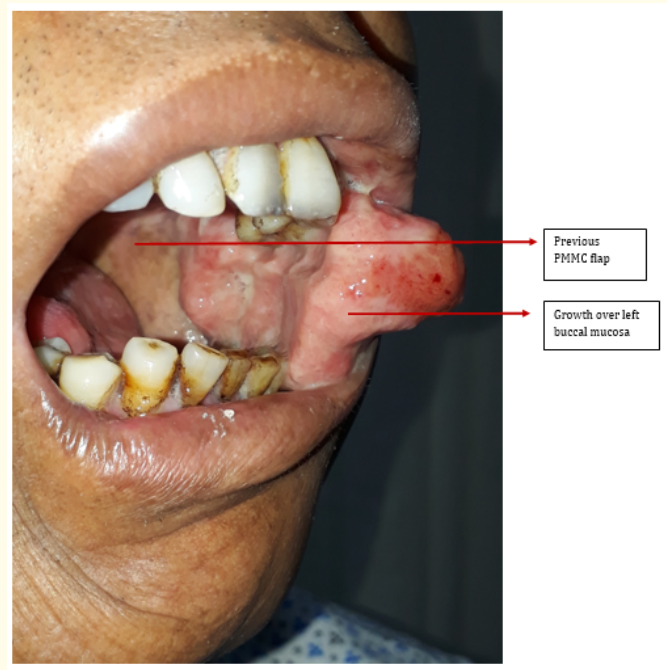

Figure 2: Clinical presentation of lesion.
On gross examination, the specimen measured $6 \times 4 \times 2 \mathrm{~cm}$. The cut surface showed an exophytic growth involving the left gingivobuccal sulcus measuring $4.5 \times 3.5 \times 1.2 \mathrm{~cm}$. It had a pink fleshy cut surface that favours a sarcomatiod carcinoma or a sarcoma more than a squamous cell carcinoma. On morphology, the tumor cells showed compact proliferation of spindle cells arranged in a storiform pattern, with predominantly lymphoplasmacytic cells infiltration (Figure 3). There was also marked cellular atypia. As the tumor was exophytic, the underneath buried squamous epithelial mucosa also showed marked reactive nuclear atypia. This might have been misinterpreted as squamous cell carcinoma in the biopsy (Figure 4). IHC was positive for Desmin (Clone D33; Dako Figure 5a), Vimentin (Clone V9; Dako - Figure 5b) indicating myofibroblastic nature. SMA (Clone IA4; Dako), CD 34 (Clone QB END/O; DAKO), Melan A (Clone A/03; Dako) were negative, which ruled out smooth muscle tumor, solitary fibrous tumor and malignant melanoma. Alk1 (Clone CD246; Dako) and S-100 (Polyclonal Rabbit anti 100; Dako) was negative. P 63 (Clone DAK- P63; Dako) was negative which ruled out epithelial malignancy.

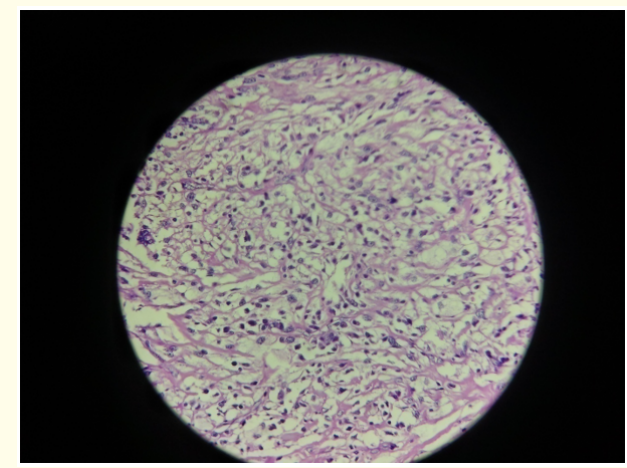

Figure 3: Hematoxylin and eosin stain $x 40$ magnification section showing inflammatory myofibroblasts and inflammatory cells.

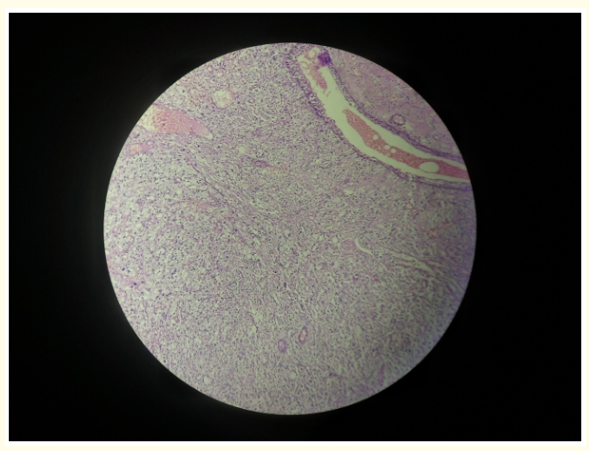

Figure 4: Hematoxylin and eosin stain $\mathrm{x} 4$ magnification section showing normal squamous epithelium with submucosa showing tumor cells. 


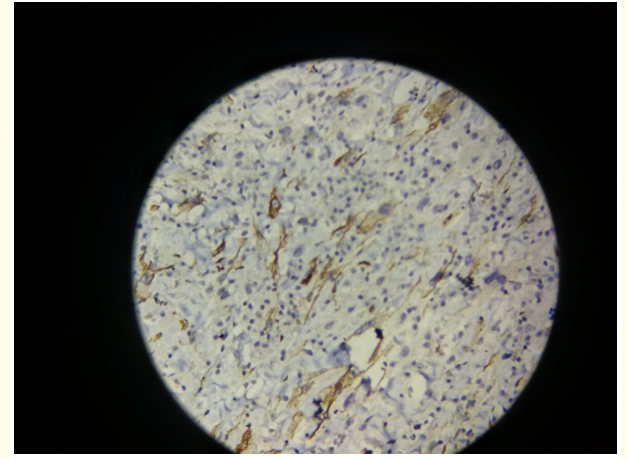

Figure 5a: x40 magnification section showing focal desmin positivity.

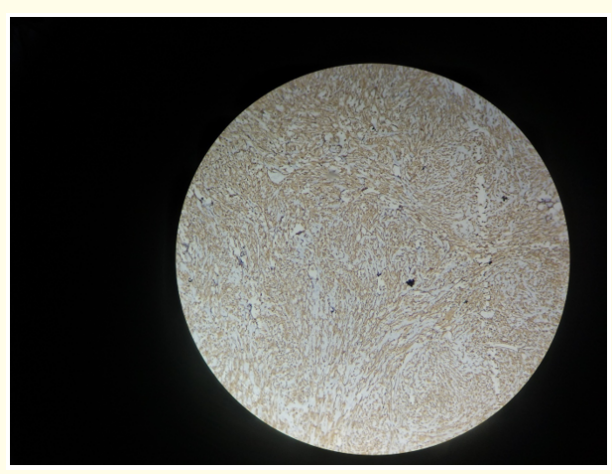

Figure 5b: Hematoxylin and eosin stain x10 magnification section showing vimentin positivity.

Hence, a final diagnosis of IMT was given. Patient had no clinical evidence of recurrence for a follow up period of 1 year (Figure 6).

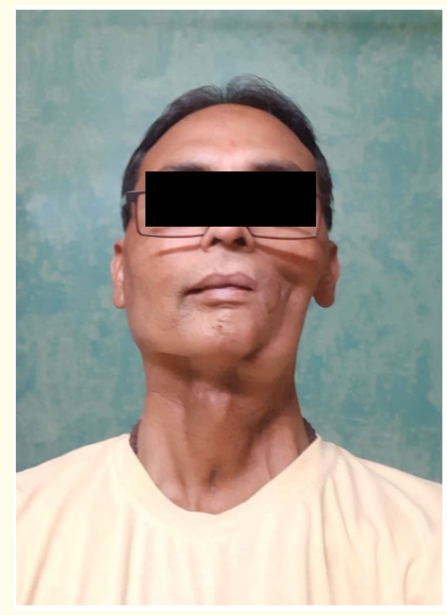

Figure 6: Follow up after 1 year.

\section{Discussion}

Inflammatory myofibroblastic tumor (IMT) is a rare lesion with literature reporting its occurrence in all parts of the body with most common involvement of lungs [1]. Oral IMT's are very rare lesions with non-specific clinical and radiologic appearance. Though many factors have been implicated, the etiology and pathogenesis of IMT remain unknown.

The diagnosis of IMT is essentially a histologic one with exclusion and clinico-pathologic co relation. The differential diagnosis of IMT includes a long list of pathologies due to its spectrum of varied histologic appearances. But for practical purposes, taking into account its main components of myofibroblasts with inflammatory cell component, the list could be limited to fibrohistiocytic or hyalinising spindle cells lesions with an inflammatory appearance such as - pseudosarcoma, myofibroma, fibromatosis, fibrous histiocytoma, nodular fascitis etc [2,3].

In 1994 WHO classified IMT as intermediate soft tissue tumor that is composed of myofibroblast-differentiated spindle cells and accompanied by numerous inflammatory cells, plasma cells, and/ or lymphocytes [4]. Coffin., et al. in 1995 [5] proposed 3 basic histologic patterns - (1) myxoid vascular and inflammatory proliferation resembling nodular fasciitis; (2) compact spindle cells proliferation resembling fibrous histiocytoma or fibromatosis and (3) dense collagen deposition with sparsely cellular components resembling a scar or desmoid tumor. In our case, the histologic architecture was that of type 2. In 1998, Coffin., et al. [1] have documented the demonstration of clonality, with reports of local recurrence and sarcomatous conversion. This has led to the classification of IMT as a truly neoplastic process [6]. But the reports of IMT in oral cavity have not documented such aggressive behaviour except for one case by Zhou., et al. [7] in which patient had IMT of maxillary sinus and had loco regional recurrence and expired due to cachexia.

Morphology and Immunoprofiling is helpful in establishing the diagnosis of IMT mainly by identification of myofibroblasts. They maybe VD (vimentin and desmin) positive, VAD (vimentin, actin, and desmin) and VA (vimentin and actin) positive. ALK (Anaplastic lymphoma kinase) is another immunohistochemical marker linked to neoplastic transformation generally used for the diagnosis of IMT. But the incidence of ALK positive IMT's has been approximately 50\% (Coffin., et al.) [1] and hence it is not a specific marker for this lesion. The collective data of oral cavity IMT's show that immunohistochemistry reactivity has been documented for vimentin, smooth muscle actin, desmin, ALK but not S-100. 
Occurrence of IMT in head and neck region is very rare and the few reports available do not have any previous history of carcinoma in the patients. We have performed a comprehensive search to include all case series and reports of IMT till date. Additional articles were included from the references when suitable. Including this case, a total of 33 cases of IMT have been reported. To the best of our knowledge there is only one other documentation in literature, by Pankaj., et al. [8] reporting the incidence of IMT in oropharynx in a known case of squamous cell carcinoma of oral cavity.

Table 1 summarizes the data of all the cases including the age, sex, site, and treatment done with follow up period.

\begin{tabular}{|c|c|c|c|c|c|c|}
\hline $\mathbf{S N}$ & Author & Subsite & Age & Sex & Treatment & Follow Up \\
\hline 1 & Rudy (1964) [9] & Mandible & 49 & $\mathrm{f}$ & Enucleation & 10 mon \\
\hline 2 & Zegarelli (1974) [10] & Mandible & 56 & $\mathrm{f}$ & Incisional biopsy & 1 year \\
\hline 3 & Acevedo (1977) [11] & Gingiva & 49 & $\mathrm{f}$ & Biopsy & - \\
\hline 4 & Liston (1981) [12] & Cheek -2 , face- 1 & 4,19 mon, 5 & $2 \mathrm{f}, 1 \mathrm{~m}$ & Incisional biopsy & 6 mon, 10 mon, - \\
\hline 5 & Earl (1993) [13] & $\begin{array}{l}\text { Buccal and submand } \\
\text { gland }\end{array}$ & 44 & $\mathrm{~m}$ & Curettage and biopsy & 2 years \\
\hline 6 & Inui (1993) [14] & Submand gland & 63 & $\mathrm{~m}$ & Enucleation & 2.5 years \\
\hline 7 & Som (1994) [15] & Max sinus (6 patients) & - & $5 \mathrm{~m}, 1 \mathrm{f}$ & - & - \\
\hline 8 & Ramachandra (1995) [16] & Cheek & 77 & $\mathrm{f}$ & Local excision & 2 years \\
\hline 9 & Shek (1996) [17] & Cheek, maxilla & 20,36 & $\mathrm{~m}, \mathrm{f}$ & $\begin{array}{l}\text { Excision biopsy, complete } \\
\text { resection }\end{array}$ & 13 mon \\
\hline 10 & Mahasin (1997) [18] & Tonsil & 41 & $\mathrm{~m}$ & Tonsillectomy & 10 mon \\
\hline 11 & Ide (1998) [19] & Buccal mucosa & 68 & $\mathrm{f}$ & Resection & - \\
\hline 12 & Ide (1998) [2] & RMT & 43 & $\mathrm{f}$ & Excision biopsy & 1 year \\
\hline 13 & Ide (2000) [3] & Tongue & 27 & $\mathrm{~m}$ & Excision & - \\
\hline 14 & Pankaj (2001) [8] & Tongue & - & - & Wide local excision & - \\
\hline 15 & Karakokm (2002) [20] & Maxilla & 54 & $\mathrm{~m}$ & - & 4 mon \\
\hline 16 & Zhou., et al. (2004) [7] & Maxillary sinus & 63 & $\mathrm{f}$ & $\begin{array}{c}\text { Partial maxillectomy + RT } \\
+ \text { chemotherapy }\end{array}$ & Died in 1 year \\
\hline 17 & Brooks (2005) [21] & Mandible & 82 & $\mathrm{f}$ & Excision & 18 mon \\
\hline 18 & Poh (2005) [22] & Mandible & 42 & $\mathrm{f}$ & Enucleation & 6 mon \\
\hline 19 & Deshingkar (2007) [23] & Maxilla & 30 & $\mathrm{f}$ & Partial maxillectomy & - \\
\hline 20 & Oh (2008) [24] & Mandible & 20 & $\mathrm{f}$ & Marginal mandibulectomy & 22 mon \\
\hline 21 & Xavier (2009) [25] & Floor of mouth & 23 & $\mathrm{f}$ & Excision & 24 mon \\
\hline 22 & Eley, watt-smith (2010) [26] & Maxilla & 29 & $\mathrm{~m}$ & Excision & 6 years \\
\hline 23 & Magill (2010) [27] & Tonsil & 28 & $\mathrm{f}$ & Laser excision & 13 mon \\
\hline 24 & Satomi (2010) [28] & Mandible & 14 & $\mathrm{f}$ & Excision & 10 years \\
\hline 25 & S y kim (2011) [29] & Maxillary sinus & 24 & $\mathrm{~m}$ & Excision & 15 mon \\
\hline 26 & Palaskar (2011) [30] & Mandible & 19 & $\mathrm{~m}$ & Excision & 6 mon \\
\hline 27 & Binmadi (2011) [31] & Maxilla & 40 & $\mathrm{f}$ & Excision & 4 mon \\
\hline 28 & Lourenco (2012) [32] & Tongue & 14 & $\mathrm{~m}$ & - & 5 years \\
\hline 29 & Routava (2013) [33] & Maxilla & 11 & $\mathrm{f}$ & Enucleation + curettage & 3 years \\
\hline 30 & Yucel (2013) [34] & Tongue & 75 & $\mathrm{~m}$ & Wide excision & $\begin{array}{l}1 \text { year, then died } \\
\text { due to heart disease }\end{array}$ \\
\hline 31 & Stringer (2014) [35] & Mandible & 16 & $\mathrm{~m}$ & Curettage & $6 \mathrm{mon}$ \\
\hline 32 & Shetty (2019) [36] & Maxilla & 29 & $\mathrm{~m}$ & Excision & - \\
\hline
\end{tabular}

Table 1: Summary of review of literature.

(m: Male; f: Female; mon: Months; RMT: Retromolar Trigone; -: Signifies the information is not available in the article). 
The age of incidence varied from a few months to 82 years. The collective data shows that IMT had a slight female predilection and was documented in all sites of oral cavity. The treatment modalities ranged from excision biopsy to wide excision and/or resection followed by adjuvant therapy. Only 1 case reported a loco - regional recurrence. Hence it could be postulated that the treatment approach for IMT's should be surgical when the resulting morbidities are acceptable.

The current case is the first of its kind reporting the occurrence of IMT in the same site with a previous history of Squamous Cell Carcinoma. It is undetermined at this point if its incidence with a history of squamous cell carcinoma is of any significance in determining its prognosis. It could probably be gleaned in the future by regular follow up.

\section{Conclusion}

In conclusion inflammatory myofibroblastic tumor is a rare entity which is successfully treated in majority of the cases by surgical management. Because of its rare incidence, histologic and radiologic similarity to a malignancy, it can be a diagnostic controversy. But with thorough understanding of the histology and immune profiling, inflammatory myofibroblastic tumor can be diagnosed accurately and managed efficiently. Further research is needed with greater no of cases to correctly classify these oral lesions and understand their prognosis better.

\section{Conflict of Interest}

Authors report no conflicts of interest related to this study.

\section{Bibliography}

1. Coffin CM., et al. "Extrapulmonary inflammatory myofibroblastic tumor: a clinical and pathological survey". Seminars in Diagnostic Pathology 15 (1995): 85-101.

2. Ide F., et al. "Inflammatory pseudotumor in the mandibular retromolar region". Journal of Oral Pathology and Medicine 27 (1998): 508-510.

3. Ide F., et al. "Sclerosing inflammatory myofibroblastic tumour of the tongue: an immunohistochemical and ultrastructural study". Oral Oncology 36 (2000): 300-304.

4. Coindre JM. "Histologic classification of soft tissue tumors (WHO, 1994)”. Annales de Pathologie 14 (1994): 426-427.

5. Coffin CM., et al. "Extrapulmonary inflammatory myofibroblastic tumor (inflammatory pseudotumor). A clinicopathologic and immune-histochemical study of 84 cases". The American Journal of Surgical Pathology 19 (1995): 859-872.
6. Su LD., et al. "Inflammatory myofibroblastic tumor: cytogenetic evidence supporting clonal origin". Modern Pathology 11.4 (1998): 364-368.

7. ZHOU Shui-hong., et al. "Inflammatory myofibroblastic tumour in the left maxillary sinus : a case report". Chinese Medical Journal 117.10 ( 2004): 1597-1599.

8. Pankaj C and Uma C. "How to manage oral inflammatory myofibroblastic tumor (inflammatory pseudotumor) letter?" Oral Diseases 7 (2001): 315-316.

9. Rudy HN., et al. "Solitary xantho- granuloma of the mandible". Journal of the American Dental Association 18 (1964): 262271.

10. Zagarelli DJ., et al. "A large dental granuloma (inflammatory pseudotumor) with unusual features: report of a case". Journal of the American Dental Association 89 (1974): 891-894.

11. Acevedo A and Buhler JE. "Plasma cell granuloma of the gingiva”. Oral Surgery, Oral Medicine, Oral Pathology, and Oral Radiology 43 (1977): 196-200.

12. Liston SL., et al. "Inflammatory pseudotumors in the buccal tissues of children". Oral Surgery, Oral Medicine, Oral Pathology, and Oral Radiology 51 (1981): 287-291.

13. Earl PD., et al. "Intraoral inflammatory pseudotumor". Oral Surgery, Oral Medicine, Oral Pathology, and Oral Radiology 76 (1993): 279-283.

14. Inui M., et al. "Inflammatory pseudotumor in the submandibular region. Clinicopathologic study and review of the literature". Oral Surgery, Oral Medicine, Oral Pathology, and Oral Radiology 76.3 (1993): 333-337.

15. Som PM., et al. "Inflammatory pseudotumor of the maxillary sinus: CT and MR findings in six cases". American Journal of Roentgenology 163.3 (1994): 689-692.

16. Ramachandra S., et al. "Inflammatory pseudotumour of soft tissues: a clinicopathological and immunohistochemical analysis of 18 cases". Histopathology 27.4 (1995): 313-323.

17. Shek AW., et al. "Inflammatory pseudotumour of the mouth and maxilla". Journal of Clinical Pathology 49.2 (1996): 164167.

18. Gangopadhyay K., et al. "Inflammatory myofibroblastic tumour of the tonsil". The Journal of Laryngology and Otology 111.9 (1997): 880-882.

19. Ide F., et al. "Intravenous myofibroblastic pseudotumour of the buccal mucosa”. Oral Oncology 34.3 (1998): 232-235. 
20. Karakök M., et al. "Inflammatory myofibroblastic tumor (inflammatory pseudotumor) of the maxillary sinus mimicking malignancy: a case report of an unusual location (is that a true neoplasm?)". Auris Nasus Larynx 29.4 (2002): 383-386.

21. Brooks JK., et al. "Oral inflammatory myofibroblastic tumor demonstrating ALK, p53, MDM2, CDK4, pRb, and Ki-67 immunoreactivity in an elderly patient". Oral Surgery, Oral Medicine, Oral Pathology, and Oral Radiology 99.6 (2005): 716-726.

22. Poh CF., et al. "Intramandibular inflammatory myofibroblastic tumor--a true neoplasm or reactive lesion?" Oral Surgery, Oral Medicine, Oral Pathology, and Oral Radiology 100.4 (2005): 460-466.

23. Deshingkar SA., et al. "Inflammatory myofibroblastic tumour of maxilla". Journal of Oral and Maxillofacial Pathology 11 (2007): 76-79.

24. Oh JH., et al. "Inflammatory pseudotumor in the mandible". The Journal of Craniofacial Surgery 19.6 (2008): 1552-1553.

25. Xavier FC., et al. "Fibronectin as an adjuvant in the diagnosis of oral inflammatory myofibroblastic tumor". Medicina Oral, Patologia Oral, Cirugia Bucal 14.12 (2009): e635-639.

26. Eley KA and Watt-Smith SR. "Intraoral presentation of inflammatory myofibroblastic tumor (pseudotumor) at the site of dental extraction: report of a case and review of the literature". Journal of Oral and Maxillofacial Surgery 68.8 (2010): 20162020.

27. Magill JC., et al. "Inflammatory myofibroblastic tumour of the tonsil: case report and literature review". The Journal of Laryngology and Otology 124.10 (2010): 1123-1125.

28. Satomi T., et al. "A successfully treated inflammatory myofibroblastic tumor of the mandible with long-term follow-up and review of the literature". Medical Molecular Morphology 43.3 (2010): 185-191.

29. Kim SY and Yang SE. "Inflammatory myofibroblastic tumor of the maxillary sinus related with pulp necrosis of maxillary teeth: case report". Oral Surgery, Oral Medicine, Oral Pathology, and Oral Radiology 112.5 (2011): 684-687.

30. Palaskar S., et al. "Inflammatory myofibroblastic tumor". Contemporary Clinical Dentistry 2.4 (2011): 274-277.

31. Binmadi NO., et al. "Oral inflammatory myofibroblastic tumor: case report and review of literature". The Open Dentistry Journal 5 (2011): 66-70.

32. Lourenço SV., et al. "Inflammatory myofibroblastic tumor of the tongue: report of an unusual case in a teenage patient". Dermatology Online Journal 18.5 (2012): 6.
33. Rautava J., et al. "Unusual case of inflammatory myofibroblastic tumor in maxilla". Case Reports in Dentistry (2013): 876503.

34. Yucel Ekici N., et al. "Inflammatory myofibroblastic tumor: a rare tumor in the tongue". Case Reports in Otolaryngology (2013): 787824.

35. Stringer DE., et al. "Intraosseous inflammatory myofibroblastic tumor in the mandible: a rare pathologic case report". The Surgical Case Reports (2014): 565478.

36. Shetty SJ., et al. "Inflammatory myofibroblastic tumor of the oral cavity: A case report and literature review". The Journal of Cancer Research and Therapeutics 15.3 (2019): 725-728.

\section{Assets from publication with us}

- Prompt Acknowledgement after receiving the article

- Thorough Double blinded peer review

- Rapid Publication

- Issue of Publication Certificate

- High visibility of your Published work

Website: www.actascientific.com/

Submit Article: www.actascientific.com/submission.php Email us: editor@actascientific.com

Contact us: +919182824667 